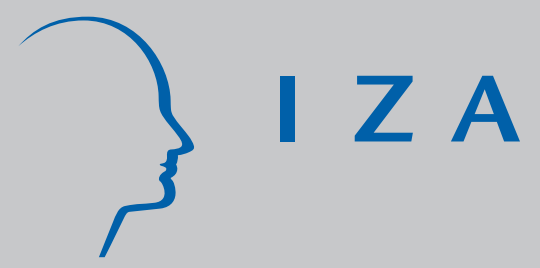

IZA DP No. 1085

J ob Tenure in Britain: Employee

Characteristics Versus Workplace Effects

Karen Mumford

Peter N. Smith

March 2004 


\title{
Job Tenure in Britain: Employee Characteristics Versus Workplace Effects
}

\author{
Karen Mumford \\ University of York \\ and IZA Bonn \\ Peter N. Smith \\ University of York
}

\section{Discussion Paper No. 1085 \\ March 2004}

\author{
IZA \\ P.O. Box 7240 \\ 53072 Bonn \\ Germany \\ Phone: +49-228-3894-0 \\ Fax: +49-228-3894-180 \\ Email: iza@iza.org
}

\begin{abstract}
Any opinions expressed here are those of the author(s) and not those of the institute. Research disseminated by IZA may include views on policy, but the institute itself takes no institutional policy positions.
\end{abstract}

The Institute for the Study of Labor (IZA) in Bonn is a local and virtual international research center and a place of communication between science, politics and business. IZA is an independent nonprofit company supported by Deutsche Post World Net. The center is associated with the University of Bonn and offers a stimulating research environment through its research networks, research support, and visitors and doctoral programs. IZA engages in (i) original and internationally competitive research in all fields of labor economics, (ii) development of policy concepts, and (iii) dissemination of research results and concepts to the interested public.

IZA Discussion Papers often represent preliminary work and are circulated to encourage discussion. Citation of such a paper should account for its provisional character. A revised version may be available on the IZA website (www.iza.org) or directly from the author. 


\section{ABSTRACT \\ Job Tenure in Britain: \\ Employee Characteristics Versus Workplace Effects*}

We consider differences in current job tenure of individuals using linked employee and workplace data. This enables us to distinguish between variation in tenure associated with the characteristics of individual employees and those of the workplace in which they work. The various individual characteristics are, as a group, found to be essentially uncorrelated with the workplace effect, however, this is not true for women and non-white employees. We find that the lower tenure associated with membership of these demographic groups is predominantly captured by workplace effects suggesting some degree of labour market segmentation in Britain.

JEL Classification: J2

Keywords: job tenure, individual, fixed-effects, voice, segmentation

Corresponding author:

Karen Mumford

Department of Economics and Related Studies

University of York

Heslington

York, YO10 5DD

United Kingdom

Email:kam9@york.ac.uk

\footnotetext{
* We thank the WERS98 sponsors - the Department of Trade and Industry, the Economic and Social Research Council, the Advisory, Conciliation and Arbitration Service and the Policy Studies Institute. They are not responsible for any of the findings or claims made in the paper. We also thank participants of the WERS and EEEG meetings, and the referees, for their helpful comments. This paper was begun whilst the authors were visitors at the Economics Program, RSSS, Australian National University. Their hospitality is, as always, gratefully acknowledged. Mumford is also grateful for financial support from the Leverhulme Foundation.
} 


\section{Introduction}

Job stability has increasingly become an issue of public and professional interest over the last two decades. A recent focus of this interest has been on the possible changes in the distribution of worker's current job tenure. In particular, authors have examined the question of whether jobs are less long lasting than they used to $b^{1}$. Whilst the results from these papers are far from uniform, they do suggest that in the US there has been some decrease in tenure (albeit modest) amongst those white males who had previously had relatively long tenure, amongst blacks and amongst young adults (Neumark et al., 1999). Similarly, the UK has seen some fall in average male tenure (Gregg and Wadsworth, 1995 and 1998), especially so amongst the lower paid (Burgess and Rees, 1996), although again these changes are not dramatic (Burgess and Rees, 1998; Nickell et al., 2002).

Much of the early literature on job tenure concentrated on the extent to which workers would move between jobs until they found a satisfactory match (Stigler, 1962; Jovanovic, 1979). Freeman (1980) and Freeman and Medoff (1984) further argued that the presence of trade unions increase individual job tenure by providing a 'voice' for grievances as well as increasing wages, both resulting in lower quit rates. More recent models argue that tenure is explicitly the outcome of the interaction of dynamic flows across both jobs and workers in the economy (Davis and Haltiwanger, 1990; Burgess et al., 1999 and 2001).

The empirical analysis of job tenure has been restricted by the nature of the available data sets which have typically provided little demographic and job-related information in addition to measures of individual tenure. In particular, none of the existing studies employ substantive linked workplace information. In this paper we compare and explore the determinants of the distribution of job tenure amongst employees in Britain. In so doing, we will consider differences in the nature of the workplaces as well as in the characteristics of the employees. This study is possible due to the recently produced linked surveys of workplaces and their employees in the British Workplace Employee Relations Survey 1998 ( WERS98).

\footnotetext{
${ }^{1}$ Tenure is one of a number of measures of job stability. We could alternatively identify quit rates or total separations (Mumford and Smith, 2003). An advantage of tenure as a measure of stability is that it captures longer run, more permanent behaviour. A drawback, as Freeman (1980) notes, is that the job-related information we have from survey data relates primarily to current job conditions rather than to earlier periods of the relationship between worker and firm. This may especially affect the interpretation of the influence of attitudinal questions.

${ }^{2}$ Department of Trade and Industry (1999). Workplace Employee Relations Survey: Cross-Section, 1998 (computer file). $4^{\text {th }}$ ed. Colchester: The Data Archive (distributor), 22 December 1999. SN: 3955.
} 
A more complete explanation of the distribution of individual and workplace tenure contains both labour supply and demand elements. Thus, the inclusion of workplace effects in addition to the labour supply determinants that feature in the work following Freeman (1980) may play an important role. We will explicitly consider the role of changes in workplace labour demand on job tenure by incorporating features of the Cabellero and Hammour (1994) model of job reallocation into our analysis at the workplace level. There is an obvious link between higher job reallocation rates and lower average tenure in a workplace since factors which increase (decrease) new hires will decrease (increase) average tenure ceteris paribus ${ }^{3}$.

In this study, we propose to concentrate on the determination of individual worker tenure given knowledge of the average tenure and characteristics of the workplace where they are employed. In particular, we are interested in discovering if low tenure individuals are concentrated in workplaces which have low average tenure (and vice versa). We also want to know whether there are identifiable characteristics of individual employees which makes them more likely to have shorter tenure than their workplace average (and vice versa). We find that individual and workplace effects explain, on the margin, about equal amounts of the variation of individual tenure. This result emphasises the importance of allowing for workplace effects. Furthermore, the two sets of variables are essentially uncorrelated with one another.

An important related issue is that of labour market segmentation. For example, it is possible that the labour market is in some ways divided into workplaces which offer better working conditions, are more attractive places of employment and are associated with longer

\footnotetext{
${ }^{3}$ Mumford and Smith (2002) explore this relationship more fully by considering net employment change and average tenure as alternative dependent variables for Australia. They find that, with the exclusion of training, variables which were found to have a significant effect on job reallocation had a significant and opposite effect on average tenure.
} 
tenure, and those that are not (Doeringer and Piore, 1971, and Taubman and Wachter, 1986). It has previously been shown that females and non-white employees have shorter tenure (Burgess 1998; Neumark et al., 1999). Here we show that in our data this result is predominantly due to the nature of the workplace they are employed in. Indeed, the shorter individual tenure (conditional on their individual characteristics) of females disappears once workplace effects are allowed for whilst that of non-whites is substantially reduced.

In section 2 of the paper we examine the econometric procedures used with linked data. We go on to discuss the determination of individual and workplace tenure job tenure in sections 3 and 4 . Section 5 evaluates the estimation results. We conclude in section 6.

\section{Estimation.}

The presence of linked employee and employer workplace information allows us to estimate models of tenure differentials across workplaces, conditional on characteristics of individual workers. The linked nature of the data sets to be employed can thus be used to good effect. Typically individual-based data sets, whilst they may include some workplace information, do not identify where more than one individual in the data is employed in any given workplace. Individual-based data sets also, typically, have limited workplace information. ${ }^{4}$ The model to be estimated is:

$$
\mathrm{T}_{i k}=\alpha_{k}+X_{i k} \beta+\mu_{i k}
$$

where the tenure of worker $i$ in workplace $k\left(T_{i k}\right)$ is explained by a set of individual characteristics $\left(X_{i k}\right)$ and a workplace fixed effect $\left(\alpha_{k}\right), \mu_{i k}$ is an iid error term ${ }^{5}$. As Bronars and Famulari (1997), Bingley and Westergaad-Nielsen (1998), and Abowd et al (1999) show, this equation can be estimated with the within estimator employed usually in panel data problems (see Greene, 1997). Workplace effects and individual characteristics are not assumed to be uncorrelated and it is possible to recover the proportional contributions of the two types of effect. We expect both types of effect to be important. ${ }^{6}$

\footnotetext{
${ }^{4}$ Two recent studies of linked datasets on wages, tenure and employment dynamics (Bronars and Famulari, 1997, and Bingley and Westergaad-Nielsen, 1998) also have very limited workplace information.

${ }^{5}$ The form of tenure model we use here is linear in the individual characteristics and workplace fixed effects. In common with Freeman (1980) and subsequent authors, we adopt this first-order Taylor approximation to a more complicated hazard function. Freeman (1980) provides evidence in favour of this approach relative to a constant hazard model.

${ }^{6}$ More generally, there may also be unobservable individual effects in equation (1). Those common to all employees in a workplace are captured in the workplace effect, $\alpha_{k}$. The remaining idiosyncratic unobservable individual effects
} 
If one is prepared to go a step further and assume that the determinants of the workplace fixed effects and the individual characteristics are uncorrelated, it is possible to estimate the determination of the workplace fixed effects. The model is therefore:

$$
\hat{\alpha}_{k}=a+Z_{k} \gamma+\varepsilon_{k}
$$

where the $\hat{\alpha}_{k}$ are generated from equation (1), $Z_{k}$ are workplace characteristics and $\varepsilon_{k}$ is an iid error term.

It is not possible with the single cross-section of linked worker and workplace information in WERS98 to allow for completely general, unconstrained estimation employing individual and workplace characteristics. Abowd et al (1999) show that under some quite restrictive assumptions, more progress can be made if the dataset has a panel format (ie., at least two cross-sections over time). ${ }^{7}$

In evaluating the estimation results we will measure the relative explanatory contribution of the sets of individual characteristics and workplace effects. We can also compare estimates which omit the workplace fixed effects (entitled OLS in the tables) and the full estimates (entitled fixed effects or FE). An issue that we can address by this comparison is that of segmentation.

Among our demographic and occupational groupings we have groups who, in variety of different papers, have been identified as more likely to be in a different labour market segmented from the remainder (such as females and non-whites, see Doeringer and Piore, 1971; Taubman and Wachter, 1986; Joshi and Paci, 1998). A test of this idea can be carried out by comparison of the coefficients between the OLS and the fixed effects results. If a demographic identifier is significant in the OLS estimates but not in the fixed effect estimates, then we can attribute the impact of membership of that demographic group to the workplace rather that to the worker's

are denoting as $\gamma_{\mathrm{i}}$ which modifies the equation to:

$$
\mathrm{T}_{i k}=\alpha_{k}+X_{i k} \beta+\gamma_{i}+\mu_{i k}
$$

It is not possible to identify these $\gamma_{\mathrm{i}}$ effects in our data and we relegate them to the residual. This will have no consequence for the estimate of $\alpha_{k}$ if the $\gamma_{i}$ are uncorrelated with these included workplace effects. We believe any biases in our estimates from this source to be small; a point we elaborate on further in discussing the results below.

${ }^{7}$ The methods we employ could therefore be extended at a later date if, and when, another wave of WERS become available. 
individual characteristic. This would be evidence suggesting segmentation.

\section{Modelling job tenure.}

The distribution of job tenure across current employees is clearly the outcome of the interaction of both supply and demand effects. At the individual level, the decision to seek and continue market employment has been well documented in the labour supply literature (Killingsworth, 1983; Jovanovic, 1979). Models of the firm's demand for labour via the process of job creation and job destruction are rarer (Davis and Haltiwanger, 1990; Caballero and Hammour, 1994 and 1996; Mortensen and Pissarides, 1994) but also well documented. Attempts to combine these job and worker flows concepts into an aggregate matching model across firms and employees are still at the empirical stage, however, and have not yet resulted in formalised theoretical models (Burgess et al., 1999 and 2001; Anderson and Meyer, 1994). Whilst tenure is the outcome of these flow processes, models of labour turnover will probably be observationally equivalent for data on job durations (Topel and Ward, 1992). We therefore follow the recent literature on tenure and adopt a holistic modelling approach.

Freeman (1980), in his discussion of the union-exit voice issue, provides a useful set of organising principles for the analysis of individual worker tenure. These are the pecuniary and non-pecuniary benefits of the current job and, in addition, the personal characteristics affecting the transactions costs of job mobility.

The pecuniary benefits of the current job are clearly dominated by the wage. However, this is obviously endogenous in the determination of tenure and it would not be valid to include it amongst the explanatory variables in regression analysis (Brown, 1989). Freeman and numbers of other authors have subsequently attempted to adjust for the simultaneity of the wage in tenure regressions (Freeman and Medoff, 1984 and Miller and Mulvey, 1991). The workplace fixed effects that we allow for could influence both wages and tenure, so we simplify the analysis by estimating a reduced form and leave the issue of wages for further work.

Non-pecuniary work benefits are hard to identify but we extend the range of variables 
used in the exit voice tenure studies by including variables that identify demographic information, job characteristics and job environment, education, and occupation. We expect that demographic information which includes family circumstances will be highly correlated with the transactions costs of job mobility. Whilst measures of education and occupation may be correlated with the value of outside opportunities. Each of the groups of variables is described in more detail below.

The most important difference between our estimates and the existing literature is the addition of workplace fixed effects. In terms of the classification above, we can anticipate that these workplace effects predominantly influence the pecuniary and non-pecuniary benefits of the current job and will be much less correlated with outside opportunities. To the extent that we find these fixed effects to be of statistical significance, this strengthens our belief in the relative importance of current-job-related information. In particular, this also raises the possible importance of the labour demand or firm initiated determinants of tenure. As discussed by Mumford and Smith (1996 and 2002), dynamic models of labour demand (such as that outlined by Cabellero and Hammour, 1994) can provide predictions of the likely impact of shocks to the demand for the firm's output. For example, if subject to a negative demand shock, the firm may choose to reduce tenure by increasing the rate of layoff whilst leaving the hiring rate unchanged. The costs of hiring and firing will play an important role here. In the current study, labour demand effects on individual tenure will be captured predominantly by the workplace fixed effects.

\section{Data and variable choice.}

The data used in this study are drawn from the British Workplace Employee Relations Survey 1998 (WERS98) ${ }^{8}$ which is the largest, currently available, survey of its type and was conducted between October 1997 and June 1998 (Cully et al., 1998). Interviews were conducted with a manager (with day-to-day responsibility for employee relations) and with a worker

\footnotetext{
${ }^{8}$ Department of Trade and Industry (1999). Workplace Employee Relations Survey: Cross-Section, 1998 (computer file). $4^{\text {th }}$ ed. Colchester: The Data Archive (distributor), 22 December 1999. SN: 3955.
} 
representative $^{9}$ (if nominated) at 2191 workplaces (all of which had more than 10 employees ${ }^{10}$ ). Employees in these workplaces were also randomly sampled (a sample size of 28,215). All of these surveys are linkable. The WERS98 was released in February, 1999, so there has been little time for studies of tenure to be undertaken using these data. There have been a limited number of studies using earlier versions of the WERS data sets (Millward et al., 1999). However, the linkable employee surveys add a major, and very valuable, component to existing studies of tenure: providing for the possibility of separating out individual from workplace effects on tenure.

We essentially have data from surveys at two different levels: the individual employee, and the workplace. We will address these in turn.

\subsection{At the individual level.}

The individual employee survey asked respondents for demographic information about themselves (such as age, education, number of children), factual information about their jobs (hours worked, employer provided training, et cetera) and to a lesser degree attitudinal questions about their job and their job environment. The overlap between these categories, especially between job characteristics and job environment, is major and is accentuated by the attitudinal nature of many of the survey questions (such as the extent of job effort and/or insecurity). We

\footnotetext{
${ }^{9}$ 'The senior lay representative of the recognised union with the most members at the workplace or if there were no recognised unions, but a joint consultative committee operated, the senior employee representative on that committee' (Cully, 1998;9).

${ }^{10}$ We do not believe that this will bias our results. Davis, Haltiwanger and Schuh $(1996 ; 66-70)$ show that the regression fallacy can make small firms/workplaces seem very different from the rest when in fact they are not, especially in respect of net employment growth (with obvious implications for tenure). In addition measurement error is proportionally more important among the smallest workplaces and sampling errors larger (Davis, Haltiwanger and Schuh, 1996; 211).
} 
have accordingly, somewhat arbitrarily, blocked the summary statistics for variables for employees in Table 1 into demographic attributes; and job characteristics (with education and occupation controls listed separately).

Considering Table 1 in more detail, column one presents the name of the variable, columns two to five present summary statistics and column six provides the variable definition. The data have been weighted to allow for stratification and clustering (Deaton,1998) and thus represent the sampling population.

It becomes immediately obvious that whilst WERS98 may be a useful data set, it is not perfect. For example, with respect to tenure respondents were asked to choose a band (5 available bands) with a maximum value of 10 years or more. If this latter band is coded at 10 years, the average tenure in Britain (tenure) is 5.36 years.

The best estimate of the average length of completed job spells, given only data on uncompleted jobs, is that (given certain assumptions) they last precisely twice the elapsed tenure period (Burgess and Rees, 1996) ${ }^{11}$. So we would expect an individual to spend on average 10.7 years in a job ${ }^{12}$. In this paper, however, we will be examining the distribution of tenure amongst those people employed. We will not be exploring the distribution of tenure over jobs ${ }^{13}$.

The demographic variables reveal an average age across workers of 39 years, $48 \%$ of the workforce is female, $3.5 \%$ non-white, and $70 \%$ married (cohabiting with spouse or partner). The

\footnotetext{
${ }^{11}$ An alternative could be to estimate retention rates, however, this would involve making the rather strong assumptions that the employment function is stable and that the arrival rate is constant over time (Neumark et al., 1999).
${ }^{12}$ Most available data on tenure is truncated, probably due to survey constraints and fears of recall error by respondents (Burgess and Rees, 1998). Gregg and Wadsworth (1998) use data from the General Household Survey for the UK to consider changes in job security over time. The GHS has limited job and workplace information but it does ask for tenure with the current employer. This information is banded up to a maximum of 40 years. Gregg and Wadsworth (1998) found, with no correction for possible recall bias, that the average job tenure was $>$ just over five years' in the UK, and the expected average job tenure was some eleven years.

${ }^{13}$ Discussion of length-biased sampling difficulties that might be involved in this latter task are provided in Chesher and Lancaster (1987) and Burgess and Rees (1996).
} 
distibution of children is fairly even across the three age bands. We would expect from the literature on discrimination (Cain, 1986; Joshi and Paci, 1998) and segmented labour markets (Doeringer and Piore, 1971) that, if these variables did have an impact on tenure then being young, female (especially with children), and non-white would all lead to shorter tenure.

Amongst the job characteristics, we include a range of variables which reflect the nonpecuniary quality of the job: home working, job sharing and flexible working time available. We believe that jobs with flexible working patterns would be more attractive to employees and be associated with longer tenure. We also include variables measuring whether the individual is employed part time, their total hours worked and if they would would prefer to work more hours. Labour supply theory suggests that working generates disutility for the employee, thus the more hours demanded by the job the more likely the worker is to be discontent and to leave, resulting in shorter tenure (Killingsworth, 1983). This prediction needs to be tempered, however, by the constraints part-time contracts put on the labour supply choices of individuals. In total, British employees on average work 36 hours per week, one in four work part-time, and $28 \%$ of employees want to work more hours. The proportions of individuals receiving employer provided training are substantial at $61 \%$. On average, these workers receive 2.5 days of this training a year. Training funded by the employer would be predominantly job specific in nature and is typically associated with longer tenure (Becker, 1975).

Union membership is still substantial in Britain (40\%). In terms of the impact of unionism on the individual, we would expect that the union would provide a voice mechanism for the individual thereby leading to less quits and longer tenure (Freeman, 1980) ${ }^{14}$. The remaining measures of job characteristics are strongly attitudinal: $48 \%$ report that their jobs are stressful; $5 \%$ that their job requires a lot of effort; and 20\% feel insecure about the future of their job.

\footnotetext{
${ }^{14}$ Unions may obviously also provide a range of other services to their members which would increase relative job satisfaction and lower the quit rate. One such service which has been found to have a significant positive impact on average tenure in the UK, but for which we do not have data, is the provision of a pension scheme (Shah, 1985 and Henley et al., 1994).
} 
The expected relationship between education and tenure is non-linear: poorer educated individuals may be clustered into low quality, short tenure employment; more highly educated individuals face a greater range of employment opportunities and are typically more mobile, both resulting in shorter tenure. Some three quarters of the British population did not proceed with formal education beyond a maximum of the end of secondary school ${ }^{15}$, although $38 \%$ have obtained an additional vocational qualification.

Occupational choice, at an individual level, is often treated in much the same way as educational outcome since they both reflect a range of variables, especially individual ability and opportunity (Filer, 1986). Our data sets only cover those currently employed so these occupational choices may be also somewhat constrained. We do not have strong priors concerning the impact of occupation on tenure. In general, we would expect less skilled occupations to be associated with shorter tenure. The occupation dummies will be included predominantly as control variables in the regression analysis and they may also help us to understand the impact of the variables capturing the work environment.

\subsection{At the workplace level.}

At the workplace level we believe that the main economic process determining average tenure is one of varying labour demand which can be captured by the creative-destructive model of Cabellero and Hamour (1984). This model has been applied in a series of job reallocation papers (Blanchflower and Burgess, 1996; Mumford and Smith, 1996) and to job reallocation and tenure in Australia (Mumford and Smith, 2003). The latter paper develops the model and related arguments at length, a further more detailed exposition is available in an appendix from the authors.

\footnotetext{
${ }^{15}$ There are many others most of whom probably did not progress beyond primary education.
} 
Cabellero and Hamour (1984) argue that the processes of job creation and destruction are profit maximising responses of firms facing continuously advancing technology and exogenous changes in the demand for their output. Firms are assumed to introduce new technology by creating a new production unit (a new job) which is a bonding of a suitable worker, capital and state-of-the-art technology. New workers are more productive and output will be accordingly higher. Once created, the technological level of a job is fixed, consequently a gap between the worker's productivity and that of new employees emerges over time. If firms do not introduce new jobs, their production processes will eventually become outdated as the skills of the longer tenured members of the labour force become relatively obsolete. When a recession hits, the derived demand for the firm's employees falls. The firm can reduce the size of its labour force by either decreasing job creation or increasing job destruction. If it adjusts entirely via less creation, the incumbent employees are, at least partially, insulated from the recession and average tenure in the workplace will rise.

The course chosen by the firm will depend on the nature of the costs involved in creation and the necessity to smooth this flow over time. This analysis suggests that average tenure is asymmetrically related to expected changes in demand for the output of the workplace; falls in demand have a positive impact which is larger than the negative impact of increases in demand on tenure (and vice versa for employment growth). Furthermore, tenure will be longer in workplaces that are larger, more capital intensive, and running training programs for their employees. These relationships will be discussed in more detail below.

The summary statistics for the workplace data are presented in Table 2. Once again the data are grouped for descriptive purposes, this time into market (or economic) variables; industrial relations indicators; and industry dummies. The data have been weighted by inverse sampling probabilities and thus represent the sampling population. Columns 2 to 5 of Table 2 present summary statistics for the full sample of workplaces (1522), column 6 provides mean values for workplaces with a disproportionately large number of females in the workforce (858 workplaces) and column 7 similarly provides mean values for workplaces with a disproportionately large number of non-whites in the workforce (485 workplaces). This 
definition of disproportionately female or non-white workplaces is where the proportion of these workers in a workplace is above the average for all workplaces. These proportions are $49 \%$ for females and $3.5 \%$ for non-white workers.

Considering market characteristics ${ }^{16}$, at the time of being surveyed Britain had moved out of recession and was growing at $1 \%$ above its average rate for the period since 1980 . This growth is reflected in $35 \%$ of the workplaces responding that the market for their main product or service was growing, with $10 \%$ believing it was declining. The figures differ in the non-white workplaces where more workplaces recorded market growth (40\%) and fewer with a decline $(6 \%)$, although these differences are not significant. The average local area unemployment rate was $4.7 \%$. British workplaces often have a formal training program in operation (41\%); and labour costs are almost half total costs (47\%). The majority of workplaces are owned by firms who operate multiple workplaces (65\%); and workplaces have 58 employees on average. Female workplaces tend to be smaller (51 employees) and non-white workplaces larger (79 employees).

In the Cabellero and Hammour (1994) framework a larger workplace would facilitate potential alternative job opportunities for worker's whose jobs had become redundant, thereby lowering actual changes in the workforce but having little effect on average job tenure. The literature on labour market segmentation (Doeringer and Piore, 1971), however, suggests that larger workplaces have greater opportunity to develop internal job ladders and establish a system of workplace industrial relations (including grievance procedures) that increase job satisfaction and lead to lower quits, thereby increasing average tenure (Rebitzer, 1986). Furthermore, in terms of both the models, any institutional arrangement which would increase the provision of workplace training (such as internal job markets) would lower job destruction and increase average job tenure.

\footnotetext{
${ }^{16}$ The size of the alpha tenure measures (the dependent variables to be used in our final stage of estimation) do not have an obvious intuitive interpretation, they are derived from our first stage of estimation and will be discussed further below.
} 
The industrial relations measures are also commensurate with the individual data: the level of union recognition is $38 \%$. It is arguable that recognition is a better measure of workplace unionism (than, for example, union density) impacting as it does on the union's ability to provide an aggregate voice in negotiations with management ${ }^{17}$. Having a written grievance procedure is common (49\%) and 17\% of workplaces have a Human Resources Manager. These figures tend to be slightly higher in the female or non-white workplaces.

Considering the industry measures, female dominated workplaces are much less likely to occur in the manufacturing, construction, electrical and transport sectors, they are more likely to occur in the public services and health sectors. The differences in the distribution of non-white workplaces is not so obvious, although there is some evidence suggesting they are less likely in the electrical sector and more likely in health and other business.

\section{Estimation Results.}

\subsection{Individual employee tenure.}

The estimation results for models of individual worker tenure are given in Table 3. Columns 1 and 3 contain the basic results. These are estimates using OLS for tenure determined only by the individuals characteristics in column 1 and additionally allowing for fixed workplace effects in column 3 .

In the employee tenure regressions we have identified distinctions between demographic characteristics, features of the particular job that the worker has, individual human capital and occupational outcome. Previous studies (eg Bronars and Famulari, 1997) have only had access to

\footnotetext{
${ }^{17}$ Since the Trades Dispute Act of 1906, Britain has encouraged a non-legalistic industrial relations environment: parties could not claim damages resulting from disputes, agreements were rarely formalised in written contracts, there is no sweeping arbitration, and collective agreements have reflected union and management strategy rather than the structure of the system itself (Whitfield et al., 1994; Mumford, 1996).
} 
demographic information. All these groups of variables can be seen to be important in explaining job tenure. Education, gender and race are all significant as are occupation, full or part-time status, hours worked and a number of job characteristics and related attitudinal variables.

Considering these results in more detail, age is significantly, positively, associated with tenure, although the impact declines with age due to the quadratic term ${ }^{18}$. Gender and race are both significant with females and non-whites having shorter tenure. In the case of females, this is some 0.16 years less; for non-whites the negative impact is larger at 0.63 years. The presence of children significantly lowers tenure, except for the presence of infants and for women with infants (children aged 4 years and below). As only those currently employed are surveyed these results probably reflect a stronger attachment to the labour market amongst those women who have chosen to remain working with an infant. Being married increases tenure by 0.2 years.

Job characteristics have an important quantitative and statistical impact on tenure in our results. Extending the analysis of Bronars and Famulari (1997), we find that the availability of job sharing has a significant and large positive impact on tenure; employer-provided training appears to reduce tenure; part-timers clearly have shorter tenure in our results; and overall hours worked has little impact except at low numbers of hours in Britain. More stressful jobs are associated with longer tenure and, most substantially, current union members have longer tenure, to the tune of more than one year. This positive relationship between tenure and membership is consistent with the union voice effect predicted by authors such as Freeman $(1980)^{19}$. Feelings of job insecurity appear to have no significant impact on tenure even when we allow for a

\footnotetext{
${ }^{18} \mathrm{As}$ with any analysis of a specific regression model, questions of robustness arise. The first concerns worker age. There is a strong relationship in the estimation results between tenure and age (this is commonly found in the literature, see Burgess, 1998). The coefficients over-estimate the behavioural impact of age given the obvious direct functional relationship between the two. A strong positive relationship with age remains, suggesting that it is behavioural. Also the impact of race and origin are of similar orders of magnitude and significance.

${ }^{19}$ As we will see below, analysis of average workplace tenure conditional on the individual characteristics in the individual tenure models suggests that the impact of unions is predominantly through individual membership. Our results also demonstrate the extent of the missing variable problem in the initial analyses of individual job tenure exemplified by the union voice literature. The impacts of gender and race are the most important effects incorrectly estimated. Equally, however, the apparent near orthogonality of the remaining variables with the workplace fixed effects means that the impact of the remaining individual variables is not altered. In particular, the union membership effect is robust which suggests support for the union voice effects on job tenure. A structural estimation of this model using linked data is clearly an avenue for future research.
} 
differential effect for those working in manual occupations.

Educational attainment has a broadly negative impact on tenure and is most striking at the highest levels. This finding supports our belief that more educated workers are more mobile but not that the less educated will also have shorter tenure (as has been found in the US, Farber, 1997). This failure to find shorter tenure amongst lower educated groups is consistent with other studies using UK data (Burgess and Rees, 1998; Gregg and Wadsworth, 1998). We also find evidence of longer tenure amongst those working in white collar occupations

A number of the effects identified in the OLS results are modified significantly once we allow for workplace fixed effects. These results are presented in column 3. Some important demographic characteristics have similarly sized coefficients in the two sets of results. The impact of age and educational achievement are insignificantly reduced in size. However, the impacts of both gender and race on tenure provide an interesting comparison between the OLS and fixed effects results. The OLS results indicate a significant negative female gender effect on tenure. They also show shorter tenure for those from a non-white background. Part-time workers also have shorter tenure. These effects are all much reduced in size and significance in the fixed effects results. Controlling for the workplace fixed effects shows that analysis of data on individuals alone would mistakenly attribute the negative impact of the type of workplace where any member of either of these groups works to their gender or racial background. Similar arguments could be made for the impact of some occupational groupings. These results provide some support for the idea of segmented labour markets discussed above.

Considering Table 4, which contains further analysis of variance, we distinguish between the contributions of individual characteristics on the one hand, and workplace effects, on the other. The fixed effects estimation results show that $42.3 \%$ of the variation in raw job tenure across workers is explained by individual characteristics and workplace effects together. Individual characteristics explain $26.9 \%$ by themselves and workplace $28.5 \%$. On the margin workplace effects explain $15.4 \%$ compared with $13.8 \%$ for individual characteristics. Comparison with results for the US in Bronars and Famulari (1997) shows a somewhat greater 
relative contribution of worker characteristics in their results. However, they only have a sample of 240 establishments which may explain the reduced relative role of establishment fixed effects in their results.

According to our results in Table 4, tenure is positively correlated across workers in any given workplace, conditional on the individual characteristics of the workers and the jobs they are in. Also, conditional differences in tenure across workplaces are quite large. Workplaces with average tenure one standard deviation above the overall mean, conditional on individual characteristics, have tenure rates 1.6 years longer than the average of 5.36 years. There does not, however, appear to be significant evidence that in general long tenure workers sort themselves into long tenure workplaces. The simple correlation between workplace average worker and job characteristics and workplaces fixed effects is 0.0495 . This figure is somewhat lower than that found for the US by Bronars and Famulari of 0.221. The largest correlations between individual characteristics and workplace fixed effects are those for gender, racial background, and some occupations (as is to be expected from comparison of the OLS and fixed effects regression results in Table 3). These results indicate some labour market segmentation.

The workplace fixed effect also includes an unobserved individual effect which is common across all employees in the workplace, however, there are remaining idiosyncratic unobserved individual characteristics which may bias our estimates (see footnote 6). For example, it may be that non-white workers who are first generation migrants from non-English speaking countries have a preference to live close to each other in enclaves (Chiswick and Miller, 2002). Once employed, these workers would be less willing to leave resulting in longer tenure. Our results would attribute this effect to being non-white and thus bias the coefficient estimate in a positive direction. If we could take this into account, the negative effect on tenure for non-whites would be even greater and workplace segregation would be more important.

In fact, however, the workplace fixed effects we find to be important in determining individual tenure are essentially uncorrelated with observed individual characteristics. It seems unlikely therefore that these workplace effects mostly capture unobserved individual 
characteristics as, according to the results in Table 4, these omitted individual features would themselves be almost entirely uncorrelated with the wide range of individual and job characteristics that we employ in our individual analysis ${ }^{20}$. We can, however, obtain some insight into which workplace characteristics are correlated with the fixed effects by analysing the workplace data. We turn to that in the next section.

\subsection{Workplace tenure.}

In this section we consider models of the workplace fixed-effects, that is average tenure in the workplace conditioning on the individual characteristics of the workers concerned. The estimates are given in Table 5. We present three sets of estimates. First, estimates for all 1522 workplaces (in column 1) and then, second, for the 858 workplaces with disproportionately female (column 3) and finally, the 485 disproportionately non-white workforces (column 5). In the final two cases, this definition of disproportionately female or non-white workplaces is where the proportion of these workers in a workplace is above the average for all workplaces. These proportions are $49 \%$ for females and $3.5 \%$ for non-white workers. Comparison of the estimates for these three samples gives us an insight into the worker tenure results above ${ }^{21}$.

First, we consider estimates for the full sample (column 1). Output demand effects have a

\footnotetext{
${ }^{20}$ It may be that women and non-white employees behave as a group (even once we have allowed for their individual characteristics) in such a way as to produce shorter tenure in their workplaces than white males do, however, we don' $t$ believe our results provide any evidence for this claim. Indeed, our results go further than the large literature of previous cross sectional studies by linking evidence for both employee characteristics and identifying the workplace effect.

${ }^{21}$ The dependent variable in Table 5 is the workplace fixed effect which is generated. As this variable is the dependent variable, therefore, there is no generated regressor problem in assessing the estimated parameters of the models reported in this table. If it were a right hand side variable then adjustments analogous to those proposed by Pagan (1984) would indeed need to be employed.
} 
significant impact on workplace average tenure. The impact of positive demand changes is to reduce average tenure whilst negative demand changes increase tenure. As the model evaluated by Mumford and Smith (2002) shows; positive demand shocks will result in reduced average tenure if workplaces predominantly choose to adjust the level of labour demand upwards by increasing hiring rather than reducing firing. Reduced demand appears to increase tenure, again suggesting that firms adjust hiring downwards rather than increase firing.

General local labour market conditions are also an important determinant of conditional workplace tenure in our results. The unemployment rate in the standard statistical region of the workplace increases tenure. The impact of increased unemployment on reducing quits makes this the expected sign. We might also expect the local unemployment rate to be an additional measure of local product market demand conditions. Given our discussion of the impact of workplace demand above, the positive effect of unemployment on tenure is reinforcing.

Two features of workplace structure are significant in the full-sample results: workplace age and multiple workplaces. Workplace age might be expected to be positively associated with average tenure by construction. However, we find (in unreported results) this effect remains significant if we restrict analysis to very long -lived workplaces. Institutional features such as well-developed industrial relations procedures in older firms can be expected to be important here. This is further supported by the significant positive impact of the existence of grievance procedures. Workplaces which are part of firms with multiple workplaces have shorter average tenure in our results which may be due to the added flexibility multiple workplaces brings to the firm when allocating workers to jobs.

Finally, in common with Bronars and Famulari (1997), we find that conditional workplace average tenure is significantly affected by the industry in which the workplace operates. From Table 5 it can be seen that there are some differences between sectors ${ }^{22}$, several industries have significantly lower tenure than the missing wholesale and retail sector category.

\footnotetext{
${ }^{22} \mathrm{~F}$-tests for the exclusion of industry effects are significant at the $1 \%$ level.
} 
Workplaces in the electrical and health sectors have the lowest average tenure, whilst none are significantly higher than the wholesale and retail sector.

Comparing the results for all workplaces (column 1) with those for disproportionately female (column 3) and disproportionately non-white (column 5) workplaces, we can see that these workplaces are reacting differently to some of the economic measures. In the general results, improved market demand leads to lower tenure suggesting firms respond by creating more jobs. This is not true for female and non-white workplaces. Similarly tenure in the female and non-white workplaces is more strongly related to the unemployment rate suggesting members of these workforces are less likely to quit given the unemployment rate. And the declining negative impact of multiple workplaces suggests workers are less likely to be relocated within the firm if they are in female or non-white dominated workplaces. Taken together these results suggest that the average tenure of workforces in female and non-white workplaces is less responsive to measures of market change.

The impact of the industrial relations indicators is similar across the three types of workplaces. Comparing industry effects in the general results with the non-white workplaces shows a similar pattern across these workplaces, however, in those industries associated with a lower average tenure the negative relationship is often stronger for non-white workplaces (the electrical, hotels, and transport sectors). The negative impact associated with the health sector is much the same, whilst non-white workplaces in the public service sector have smaller decline in tenure. Typically this pattern of industry effects is not reproduced for female workplaces.

The one industry where the direction of the impact on average tenure is significantly reversed in across our workplace categories is manufacturing, in general this sector is associated with lower average tenure. However, female dominated workplaces in manufacturing have higher average tenure and this effect is stronger in non-white workplaces.

\section{Conclusion}

This paper examines the determination of individual and workplace tenure employing new linked 
data sets which has allowed for a more complete analysis of the determinants of job tenure. Using a fixed effects estimator, we find that a range of demographic, job related, educational, and occupation variables are important for explaining individual job tenure. We also find strong evidence of a positive impact of union membership on individual job tenure. This is consistent with the union voice literature, although our approach is different to those studies.

Workplace fixed effects explain as much of the variation in individual tenure as the measured individual characteristics in our study. These two groups of variables are essentially uncorrelated implying that the measured individual characteristics of long tenure workers are not closely related with the features of long tenure workplaces. However, we do find the negative impact of gender and race on tenure, that is well documented in the existing literature and appears strongly significant in estimates excluding workplace effects, is offset when workplace effects are included. We interpret this as evidence in favour of job segmentation.

We find, when exploring workplace average tenure conditioning on the individual characteristics of the workers, that tenure is longer in workplaces facing reduced market demand and higher local area unemployment indicative of mobile workforces. Workplaces with disproportionately female and non-white workforces are, however, less responsive to these measures of market change. Furthermore, of those industries with low average tenure, tenure is even lower in non-white workplaces. Future work, possibly including linked panel data, could elaborate more fully on the nature of these low tenure workplaces.

\section{References.}

Abowd, J.M. Kramarz, F. and Margolis, D.N. 1999. 'High wage workers and high wage firms.' Econometrica 67(2), 251-334.

Anderson, P. A. and Meyer, B. B. 1994. 'The Extent and Consequences of Job Turnover.' In Baily, N.B, Reiss, P.C. and Winston, C. (Editors) Brookings Papers in Economic Activity: Microeconomics 1994 . Brookings Institution, Washington, D.C.

Becker, G.1975. Human Capital $2^{\text {nd }}$ Edition. University of Chicago Press, Chicago.

Bingley, P. and Westergaad-Nielsen, N. 1998. 'Establishment tenure and worker turnover.' 
Mimeo Aarhus Business School.

Blanchflower, D. G. and Burgess. S.M. 1996. 'Job creation and job destruction in Great Britain in the 1980s.' Industrial and Labor Relations Review 50(1),17-38.

---- 1998. 'New technology and jobs: Comparative evidence from a two country study.' Economics of Innovation and New Technology 52(4), 109-138.

Bronars, S.G. and Famulari, M. 1997. 'Wage, tenure and wage growth variation within and across establishments.' Journal of Labor Economics 15(2), 285-317.

Brown, J. 1989. 'Why do wages increase with tenure.' American Economic Review 79, 971-999.

Burgess, S. 1998. 'The reallocation of labour: An international comparison using job tenure data.' Mimeo, Department of Economics, University of Bristol.

Burgess, S. and Rees, H. 1996. 'Job tenure in Britain, 1975-1992.' Economic Journal 106(435), 809-816.

Burgess, S. and Rees, H. 1997. 'Transient jobs and lifetime jobs: Dualism in the British labour market.' Oxford Bulletin of Economics and Statistics 59(3); 309-328.

Burgess, S. and Rees, H. 1998. 'A disaggregate analysis of the evolution of job tenure in Britain, 1975-1993.' British Journal of Industrial Relations 36(4), 629-655.

Burgess, S. Lane, J. and Stevens, D. 1999. 'Job flows, worker flows and churning.' Journal of Labor Economics 18(3); 473-502.

---- 2001. 'Churning dynamics: An analysis of hires and separations at the employer level.' Labour Economics 8(1); 1-15.

Caballero, R.J. and Hammour, M.L. (1994). 'The cleansing effect of recessions.' American Economic Review 84(5); 1075-1084.

Cain, G. C. 1986. 'The economic analysis of labor market discrimination: A survey.' in Ashenfelter, Orley and Layard, Richard (editors). Handbook of Labor Economics. (North Holland, Amsterdam), 693-785.

Chesher, A. and Lancaster, T. 1987. 'The estimation of models of labour market behaviour.' Review of Economic Studies 50, 609-624.

Chiswick, B.R. and Miller, P.W. 2002. 'Do enclaves matter in immigrant adjustment.' IZA Discussion Paper 449.

Cully, M. A. O'Reilly, A. Millward, Forth, J. Woodland, S. Dix, G. and Bryson, A. 1998. The 1998 workplace employee relations survey: first findings. Department of Trade and Industry.

Davis, S. and Haltiwanger, J. 1990. 'Gross job creation and destruction: Microeconomic Evidence and macroeconomic implications.' NBER Annual 5; 123-168.

Davis, S. Haltiwanger, J. and Schuh, S. 1996. Job Creation and Job Destruction. MIT Press: Cambridge, USA.

Deaton, A. 1998. The Analysis of Household Surveys. A Microeconometric Approach to Development Policy. World Bank. John Hopkins University Press, Baltimore.

Department of Trade and Industry. 1999. Workplace Employee Relations Survey: Cross-Section, 1998 (computer file). $4^{\text {th }}$ ed. Colchester: The Data Archive (distributor), 22 December 1999. SN: 3955.

Doeringer, P. B. and Piore, M.J. 1971. Internal labor markets and manpower analysis. 
D.C.Heath, Massachusetts, USA.

Filer, R. 1986. 'The role of personality and tastes in determining occupational structure.' Industrial and Labor Relations Review 39, 412-424.

Freeman, R. 1980. 'The exit-voice tradeoff in the labor market: Unionism, job tenure, quits and separations.' Quarterly Journal of Economics 94(4), 643-674.

Freeman, R. and Medoff. J. 1984. What do unions do? Basic Books, New York.

Greene,. W.H. 1997. Econometric analysis. Third edition. Prentice Hall International, New Jersey.

Gregg, P. and Wadsworth, J. 1995. 'A short history of labour turnover, job tenure and job security, 1975-1993.' Oxford Review of Economic Policy 11(1), 73-90.

----- 1998. 'Job tenure in the UK 1975-1997.' LSE Working Paper 967.

Henley, A. Disney, R. and Carruth, A. 1994. 'Job tenure and asset holdings.' Economic Journal 104(423), 338-349.

Joshi, H. and Paci, P. 1998. Unequal pay for men and women. MIT Press, Cambridge Massachusetts.

Jovanovic, B. 1979. 'Job matching and the theory of turnover.' Journal of Political Economy 87, 685-709.

Killingsworth, M. 1983. Labour supply. Cambridge University Press, Cambridge UK.

Konings, J. 1995. Job creation and job destruction in the U.K. manufacturing sector. Oxford Bulletin of Economics and Statistics 57, 5-24.

Miller, P. and Mulvey, C. 1991.' Australian evidence on the exit/voice model of the labor market.' Industrial and Labor Relations Review 45(1), 44-57.

Millward, N. Woodland, S. Bryson, A. Forth, J. and Kirby, S. 1999. 'A bibliography of research based on the British Workplace Industrial Relations Survey Series.' Mimeo, National Institute for Economic and Social Research, November.

Mortensen, D and Pissarides, C. 1994. 'Job creation and job destruction in the theory of unemployment.' Review of Economic Studies 61, 397-416.

Mumford, K. 1996. 'Arbitration and ACAS in Britain: A historical perspective.' British Journal of Industrial Relations 34(2), 287-306.

Mumford, K. and Smith, P.N. 1996. Job reallocation: Theory and workplace evidence.' University of York, Discussion Papers in Economics 96/46.

----- 2003. Job reallocation, employment change and average job tenure: Theory and workplace evidence from Australia. Forthcoming, Scottish Journal of Political Economy.

Nickell, S.Jones, T. and Quintini. G. 2002. 'A picture of the job insecurity facing British men.' Economic Journal 112(476), 1-27.

Neumark, D. Polsky, D. and Hansen, D, 1999. 'Has job stability declined yet? New evidence for the 1990s.' Journal of Labour Economics 17(4), S29-S64.

Pagan, A. 1984. 'Econometric issues in the analysis of regressions with generated regressors.' International Economic Review 25(1), 221-247.

Rebitzer, J.B. 1986. 'Establishment size and tenure.' Industrial Relations 25(3), 292-302.

Shah, A. 1985. 'Are wage incentives and unionism important determinants of job tenure.' Oxford Economic Papers 37, 643-658. 
Stigler, G. 1962. 'Information in the labor market.' Journal of Political Economy 70(1); S94S105.

Taubman, P. and Wachter, M. 1986. 'Segmented Labor Markets.' in Ashenfelter, O. and Layard, R. (Editors). Handbook of Labor Economics Volume 2. North-Holland, Amsterdam.

Topel, M. and Ward, M. 1992. 'Job mobility and the careers of young men.' Quarterly Journal of Economics 107(2), 439-479.

Whitfield, K.. Marginson, P. and Brown, W. 1994. Workplace industrial relations under different regulatory systems: A survey-based comparison of Australia and Britain.' British Journal of Industrial Relations 32(3), 319-339. 


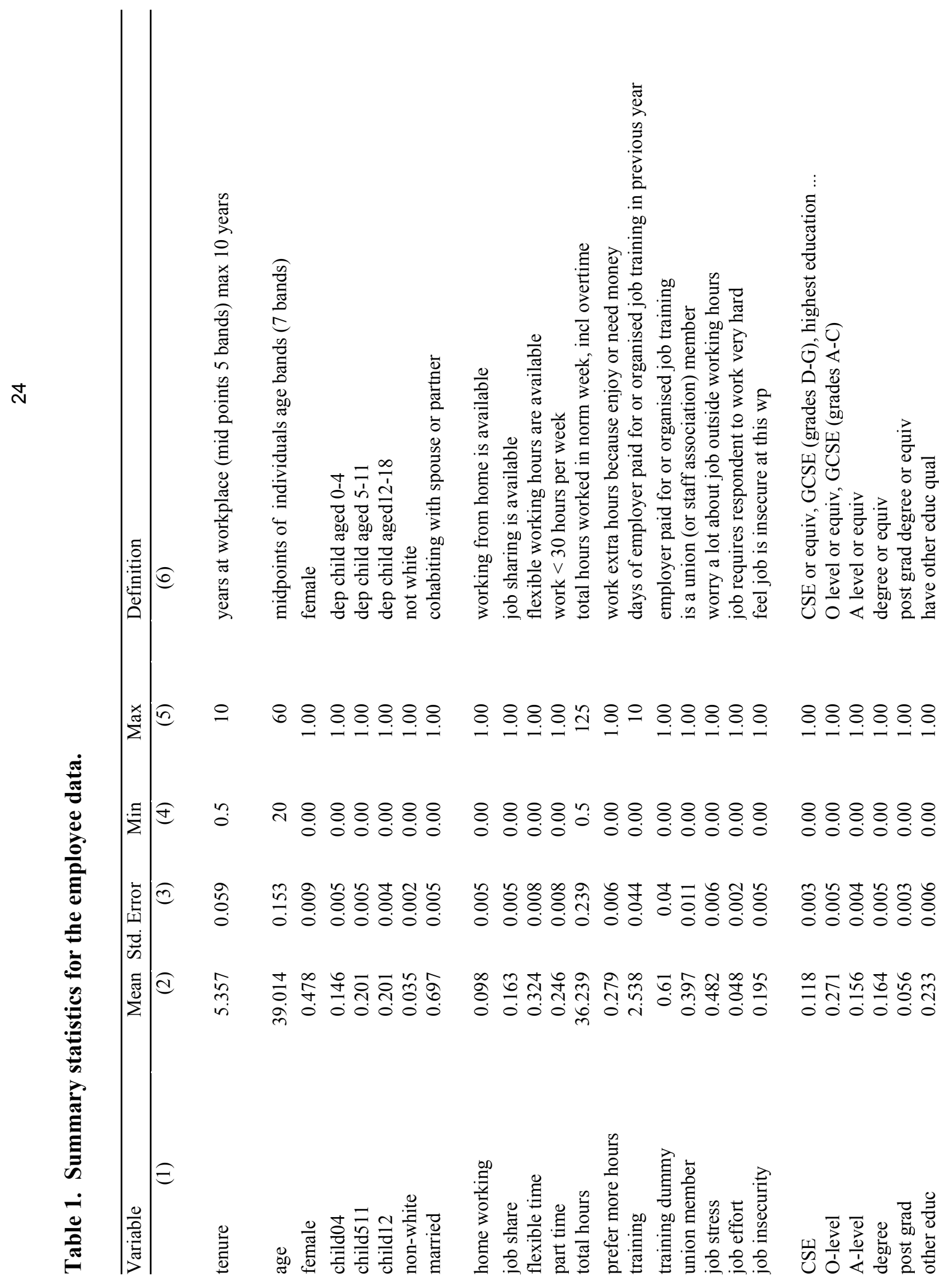




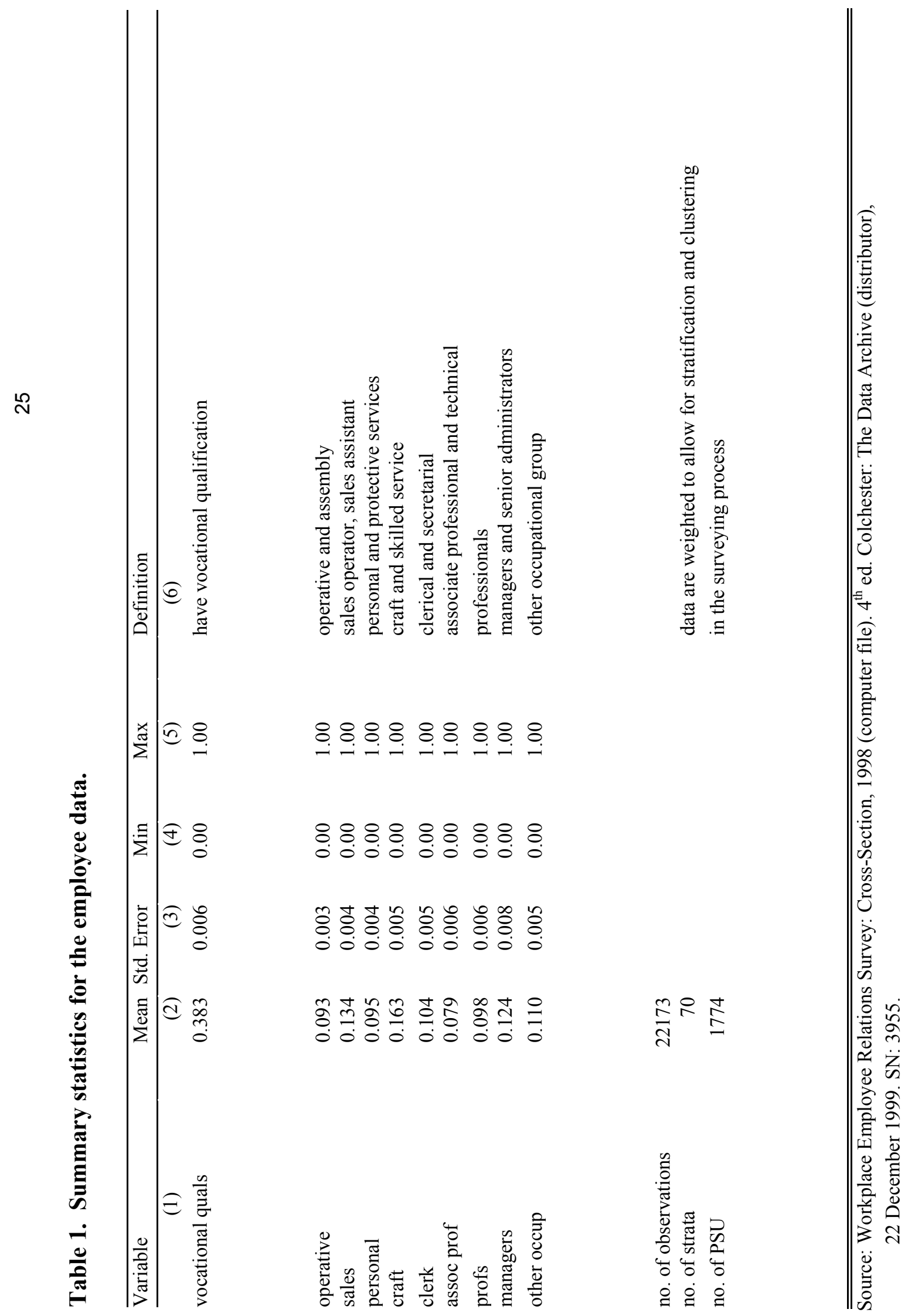




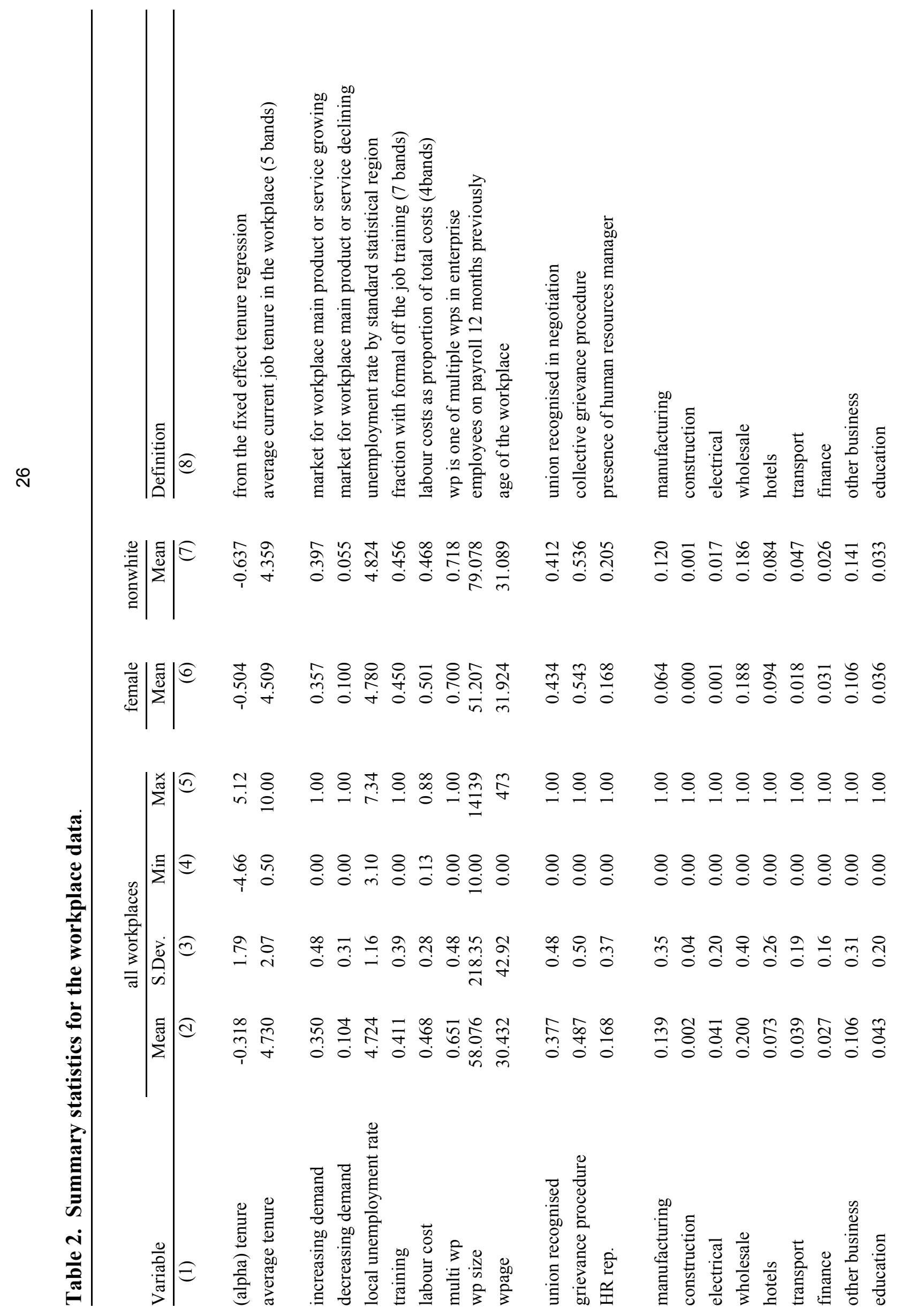




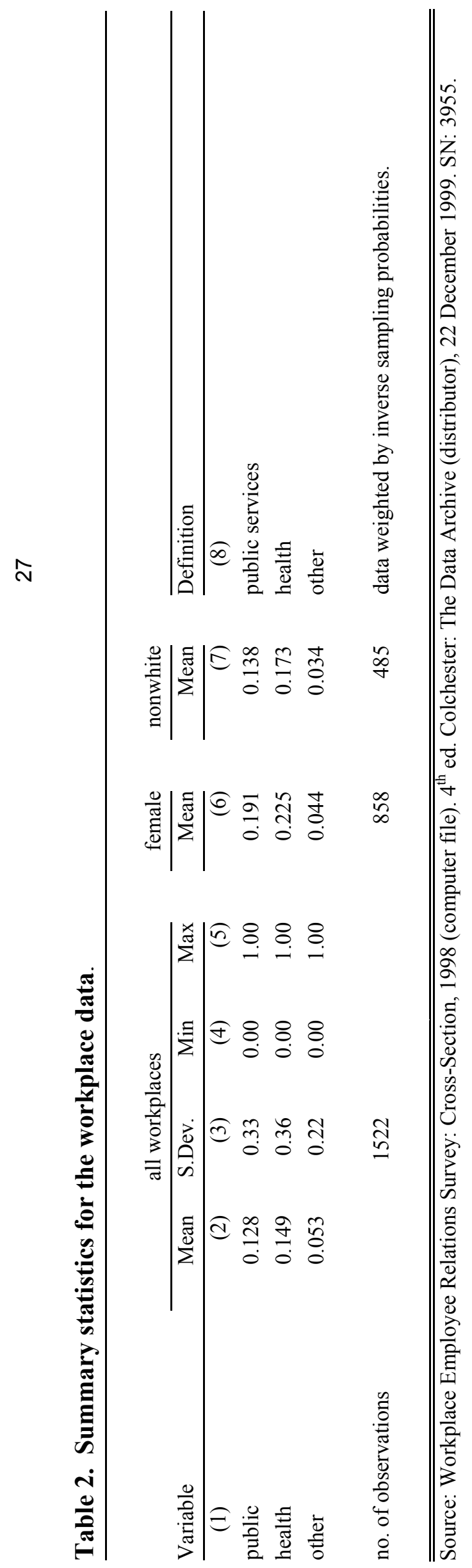


Table 3. Employee tenure.

\begin{tabular}{|c|c|c|c|c|}
\hline \multirow[t]{3}{*}{ tenure } & \multicolumn{2}{|l|}{ OLS } & \multicolumn{2}{|c|}{ Fixed Effect } \\
\hline & Coef. & t-value & Coef. & t-value \\
\hline & (1) & (2) & (3) & (4) \\
\hline age & 0.266 & $13.89 * *$ & 0.252 & $13.35 * *$ \\
\hline $\operatorname{age}^{2}(\mathrm{X} 100)$ & -2.062 & $-8.53 * *$ & -1.957 & $-8.33 * *$ \\
\hline female & -0.160 & $-1.99 * *$ & 0.057 & 0.73 \\
\hline child04 & -0.021 & -0.20 & -0.043 & -0.38 \\
\hline child512 & -0.191 & $-2.33 * *$ & -0.163 & $-1.97 * *$ \\
\hline child13 & -0.303 & $-3.62 * *$ & -0.301 & $-3.69 * *$ \\
\hline female*child04 & 0.393 & $2.41 * *$ & 0.434 & $2.63 * *$ \\
\hline non-white & -0.634 & $-4.07 * *$ & -0.407 & $-2.19 * *$ \\
\hline married & 0.243 & $3.41 * *$ & 0.171 & $2.32 * *$ \\
\hline home working & -0.064 & -0.54 & 0.035 & 0.32 \\
\hline job share & 0.228 & $2.63 * *$ & 0.283 & $3.24 * *$ \\
\hline flexible time & -0.013 & -0.17 & -0.021 & -0.29 \\
\hline part time & -0.522 & $-3.40 * *$ & -0.351 & $-2.31 * *$ \\
\hline total hours & 0.021 & 1.41 & 0.015 & 1.20 \\
\hline total hours $2(\mathrm{x} 100)$ & -0.029 & $-1.74 *$ & -0.009 & -0.60 \\
\hline prefer more hours & 0.061 & 0.82 & -0.061 & -0.81 \\
\hline training & -0.070 & $-6.28 * *$ & -0.074 & $-6.61 * *$ \\
\hline union member & 1.520 & $18.43 * *$ & 1.238 & $14.49 * *$ \\
\hline job stress & 0.444 & $6.64 * *$ & 0.486 & 7.33 ** \\
\hline job effort & -0.111 & -0.78 & -0.114 & -0.85 \\
\hline insecure & -0.075 & -0.78 & -0.078 & -0.80 \\
\hline insecure*manual & 0.100 & 0.63 & 0.042 & 0.25 \\
\hline other education & 0.038 & 0.29 & -0.033 & -0.24 \\
\hline olevel & -0.235 & $-1.97 * *$ & -0.253 & $-2.29 * *$ \\
\hline alevel & -0.324 & $-2.49 * *$ & -0.369 & $-2.86 * *$ \\
\hline degree & -1.004 & $-6.60 * *$ & -0.966 & $-6.44 * *$ \\
\hline postgrad & -1.661 & $-9.08 * *$ & -1.567 & $-8.55 * *$ \\
\hline vocational qual. & -0.135 & $-2.10 * *$ & -0.102 & -1.58 \\
\hline sales & 0.607 & $3.38 * *$ & 0.635 & $3.43 * *$ \\
\hline personal services & 0.688 & $3.95 * *$ & 0.664 & $3.63 * *$ \\
\hline skilled/crafts & 0.726 & $4.34 * *$ & 0.511 & $2.78 * *$ \\
\hline clerk & 0.337 & $2.13 * *$ & 0.309 & $1.86 *$ \\
\hline assoc professional & 0.734 & $3.98 * *$ & 0.481 & $2.59 * *$ \\
\hline professional & -0.244 & -1.31 & 0.070 & 0.36 \\
\hline manager & 0.252 & 1.31 & -0.138 & -0.67 \\
\hline other occupation & -0.296 & $-1.95 *$ & -0.189 & -1.14 \\
\hline constant & -2.378 & $-5.46 * *$ & -2.006 & $-4.41 * *$ \\
\hline \multirow[t]{2}{*}{ Number of obs } & & 22173 & & 22173 \\
\hline & $F(36,22136)$ & $170.79 * *$ & $F(36,20363)$ & 73.66 ** \\
\hline R-squared & & 0.27 & & 0.42 \\
\hline Adj R-squared & & & & 0.37 \\
\hline Number strata & & 70 & & 70 \\
\hline Number PSU & & 1774 & & 1774 \\
\hline
\end{tabular}

Source: Workplace Employee Relations Survey: Cross-Section, 1998 (computer file). $4^{\text {th }}$ ed. Colchester: The Data Archive (distributor), 22 December 1999. SN: 3955. Data are weighted to allow for stratification and clustering in the surveying process. *significant at $90 \%$ and **significant at $95 \%$ confidence levels. 
Table 4. Variance decomposition.

tenure

\section{Fraction of variance explained}

$\begin{array}{ll}\text { individual characteristics and workplace fixed effects } & 0.423\end{array}$

$\begin{array}{ll}\text { individual characteristics (number) } & 0.269\end{array}$

workplace effects (number)

$0.285 \quad(1774)$

\section{Marginal fraction of variance explained}

individual characteristics

0.138

workplace fixed effects

0.154

\section{Standard deviations}

individual characteristics

across workers

across workplaces

1.124

workplace fixed effects

\section{Correlations}

individual characteristics

0.0495

across workplaces and workplace fixed effects

Source: Workplace Employee Relations Survey: Cross-Section, 1998 (computer file). $4^{\text {th }}$ ed. Colchester: The Data Archive (distributor), 22 December 1999. SN: 3955. Data are weighted to allow for stratification and clustering in the surveying process. 


$\frac{\text { all workplaces }}{\text { Coeff. t-value }}$

(1)

$\begin{array}{rl}-0.402 & -4.02 * * \\ 0.817 & 5.29 * * \\ 0.087 & 2.24 * * \\ 0.088 & 0.68 \\ -0.060 & -0.28 \\ -0.564 & -5.21 * * \\ 0.230 & 1.10 \\ 0.225 & 2.05^{* *}\end{array}$

increasing market

decreasing market

local unemployment rate

training

labour cost

multiple workplaces

workplace size (X1000)

workplace age (X100)

union recognition

grievance procedure

HR rep.

manufacturing

construction

electrical

hotels

transport

finance

other business

education

public

health

other

constant

No. of obs

$\begin{array}{rl}-0.031 & -0.26 \\ 0.318 & 3.12 * * \\ 0.131 & 1.03\end{array}$

$-0.378 \quad-2.36 * *$

0.580

0.57

$-0.989$

$-4.04 * *$

$-0.563$

$-2.89^{* *}$

$-0.336$

$-1.35$

$-0.490$

$-1.68 *$

$-0.684$

$-3.86^{* *}$

$-0.093$

$-0.34$

$-0.736$

$-3.61 * *$

$-1.003$

$-5.72 * *$

$-0.009$

$-0.04$

$-0.080$

$-0.34 *$

1522

$\mathrm{F}(22,1499)$

R-squared

Adj $R^{2}$

7.5 **

0.0992

0.086

$\begin{array}{rl}-0.137 & -1.12 \\ 0.662 & 3.35^{* *} \\ 0.113 & 2.32^{* *} \\ -0.260 & -1.63 \\ 0.240 & 0.92 \\ -0.378 & -2.62 * * \\ 0.229 & 0.75 \\ 0.103 & 0.85\end{array}$

$\begin{array}{ll}0.190 & 1.44\end{array}$

$\frac{\text { disp. female }}{\text { Coeff. t-value }}$

(3)

(4)

$0.901 \quad 3.31 * *$

$0.1742 .86 * *$

$0.4332 .56 * *$

$0.389 \quad 1.37$

$\begin{array}{ll}-0.041 & -0.27\end{array}$

$0.089 \quad 0.53$

$-0.501-4.20 * *$

$\begin{array}{ll}-0.216 & -1.52 \\ 0.458 & 3.79 * * \\ 0.232 & 1.50\end{array}$

0.6712 .48 **

$-0.357$

$-0.099$

$-0.102$

0.025

0.330

$-0.290$

0.247

$-0.158$

$-0.484$

0.841

$-0.956$

$-0.15$

$-0.06$

$-0.46$

0.06

0.98

$-1.27$

0.70

$-0.68$

$-2.37 * *$

$2.82 * *$

$-3.06^{* *}$

858

$\mathrm{F}(22,835)$

$4.8^{* *}$

0.1123

0.089
$0.146 \quad 0.86$

$0.340 \quad 2.54 * *$

$0.145 \quad 0.95$

$1.204 \quad 4.91^{* *}$

$\begin{array}{ll}-0.453 & -0.28\end{array}$

$-1.345-2.89 * *$

$-0.786-3.20 * *$

$-0.293 \quad-0.96$

$-0.579 \quad-1.52$

$-0.620-2.78 * *$

$-0.211 \quad-0.56$

$-0.566-2.07 * *$

$\begin{array}{ll}-0.298 & -1.34\end{array}$

$0.001 \quad 0.00$

$-1.877-5.02 * *$

485

$\mathrm{F}(22,462)$

$8.19^{* *}$

0.2806

0.2463

Source: Workplace Employee Relations Survey: Cross-Section, 1998 (computer file). $4^{\text {th }}$ ed. Colchester: The Data Archive (distributor), 22 December 1999. SN: 3955. Data are weighted to allow for stratification in the surveying process. *significant at $90 \%$ and $* *$ significant at $95 \%$ confidence levels. 